\title{
New Insights on Subseasonal Arctic-Midlatitude Causal Connections from a Regularized Regression $\operatorname{Model}^{\mathscr{O}}$
}

\author{
MARIE C. MCGRAw and ElizABeth A. BARNES \\ Department of Atmospheric Science, Colorado State University, Fort Collins, Colorado
}

(Manuscript received 19 February 2019, in final form 13 September 2019)

\begin{abstract}
Arctic-midlatitude teleconnections are complex and multifaceted. By design, targeted modeling studies typically focus only on one direction of influence-usually, the midlatitude atmospheric response to a changing Arctic. The two-way, coupled feedbacks between the Arctic and the midlatitude circulation on submonthly time scales are explored using a regularized regression model formulated around Granger causality. The regularized regression model indicates that there are regions in which Arctic temperature drives a midlatitude circulation response, and regions in which the midlatitude circulation drives a response in the Arctic; however, these regions rarely overlap. In many regions, on submonthly time scales, the midlatitude circulation drives Arctic temperature variability, highlighting the important role the midlatitude circulation can play in impacting the Arctic. In particular, the regularized regression model results support recent work that indicates that the observed high pressure anomalies over Eurasia drive a significant response in the Arctic on submonthly time scales, rather than being driven by the Arctic.
\end{abstract}

\section{Introduction}

As the Arctic continues to warm at a pace that outstrips the rest of the globe, questions of Arctic influence on the weather and climate of lower latitudes abound. Often, Arctic-midlatitude climate studies emphasize the impacts of Arctic variability upon the midlatitude circulation, with numerous studies linking Arctic warming to changes in midlatitude temperature variability and extremes (e.g., Screen et al. 2015; Ayarzagüena and Screen 2016; Blackport and Kushner 2017), the jet streams (e.g., Deser et al. 2010; Butler et al. 2010; Peings et al. 2017; Ronalds et al. 2018; Zappa et al. 2018; Screen et al. 2018), and large-scale circulation patterns (e.g., Overland et al. 2015; Blackport and Kushner 2017; Screen et al. 2018). However, the midlatitude circulation also

\footnotetext{
Supplemental information related to this paper is available at the Journals Online website: https://doi.org/10.1175/JCLI-D-190142.s1.

${ }^{\text {a }}$ Current affiliation: Department of Atmospheric Science, University of Washington, Seattle, Washington.
}

Corresponding author: Marie C. McGraw, mmcgraw@atmos. colostate.edu impacts Arctic weather and climate. Moist air intrusions from lower latitudes have been linked to reductions in sea ice extent and thickness (e.g., Park et al. 2015a,b; Woods and Caballero 2016; Mortin et al. 2016; Burt et al. 2016), Arctic surface temperature variability (e.g., Woods et al. 2013; Messori et al. 2018), and changes in upperocean heat content (e.g., Park et al. 2015a). These moisture intrusions into the Arctic have been attributed to the large-scale midlatitude circulation features, such as Rossby wave breaking (e.g., Woods et al. 2013; Liu and Barnes 2015), atmospheric rivers (e.g., Newman et al. 2012; Baggett et al. 2016), and even tropical convection (e.g., Lee 2014; Baggett and Lee 2017). Warming in the Arctic has also been driven by latent energy transport (e.g., Graversen and Burtu 2016) and warm air advection (e.g., Messori et al. 2018). Thus, the Arctic and the midlatitudes influence and drive variability in each other, with both directions having substantial impacts.

Such issues of cause and effect are often probed in observational analyses that primarily use techniques such as compositing or regression/correlation analysis to try to understand relationships and how they might evolve over time. These approaches can indicate how variables might change with each other, but cannot indicate the direction of the relationship, particularly in the presence of autocorrelation; thus, the directionality 
of the relationship is often assumed but can be difficult to confirm. Cause and effect are also explored in targeted atmospheric modeling studies, where the model is externally forced (e.g., by sea ice loss), and the atmospheric response to that forcing is evaluated. However, these targeted modeling studies by design typically focus on one direction of influence in order to more fully understand the response to a specific forcing. In the case of Arctic-midlatitude interactions, for example, many targeted modeling experiments explore the influence of a warmer or sea ice-reduced Arctic on the midlatitude circulation. They simulate Arctic warming and/or sea ice loss through many approaches, such as adjusting surface heat fluxes to mimic a reduced-ice ocean (e.g., Oudar et al. 2017), continually nudging sea ice to some target value (e.g., Smith et al. 2017; McCusker et al. 2017), reducing the albedo of the sea ice (e.g., Blackport and Kushner 2016, 2017), or simply applying a warm anomaly to the lower atmosphere (e.g., Butler et al. 2010) [see box 1 in Screen et al. (2018) for more discussion of the different approaches to modeling Arctic warming and sea ice loss]. These different approaches have one thing in common-the Arctic is continually forced to a certain state (warm air temperatures, increased heat fluxes, or a certain sea ice state), regardless of what the atmosphere may be doing. Thus, while the Arctic is able to modify the atmospheric circulation, the atmospheric circulation is ultimately limited in its ability to impact the Arctic. However, we know that the atmospheric circulation does impact the Arctic climate-and thus, a comprehensive understanding of Arctic-midlatitude climate dynamics must ultimately account for the circulation's ability to modify Arctic climate.

While targeted modeling studies are designed to analyze one direction of influence, causal discovery-based approaches can augment model experiments by facilitating the simultaneous analysis of both directions of influence-Arctic variability on midlatitude circulation, and midlatitude circulation on Arctic variability. Causal discovery methods strive to identify cause and effect relationships in climate data, and represent them with graphical models [see Ebert-Uphoff and Deng (2012) and Runge et al. (2019) for an overview of causal discovery analysis in climate sciences]. These approaches are not intended as a replacement for the physical insights that well-designed modeling experiments can provide - rather, they can be used as a complementary tool to identify key causal relationships and to analyze multiple pathways of influence within a system.

One method of identifying causality uses the Granger causality framework (Granger 1969). This approach studies existing model output or reanalysis products to determine cause-effect relationships based on evaluation of added variance explained-that is, does the incorporation of some lagged variable $X$ significantly improve the predictability of some variable $Y$, beyond $Y$ 's ability to predict itself? The Granger causality framework has been applied to climate science problems in recent years (see Attanasio et al. 2013; McGraw and Barnes 2018, and references therein); and in particular, to Arctic-midlatitude climate dynamics. Strong et al. (2009) and Matthewman and Magnusdottir (2011) study the relationship between sea ice and large-scale Northern Hemisphere atmospheric variability with a vector autoregression (VAR) model. Kretschmer et al. (2016) identify key Arctic predictors of the wintertime circulation using a causal network-based approach to assess the strength of the predictors. Samarasinghe et al. (2018) study the relationship between Arctic temperatures and the jet streams using three different causal discovery approaches, and they identify positive feedback loops between Arctic temperature and North Pacific jet position and strength on submonthly time scales.

In this paper, similar to the works mentioned in the previous paragraph, we apply a regression model formulated around Granger causality in order to explore the submonthly, two-way feedbacks between the Arctic and the midlatitude circulation. Our approach allows for the simultaneous analysis of the two-way feedbacks between the Arctic and the midlatitude circulation that are not fully represented in targeted climate model experiments. In contrast to reanalysis-based studies that typically use standard lagged linear regression analysis, our use of the Granger causality framework accounts for the persistence of memory due to autocorrelation and frames these relationships in terms of added predicted power. As in Samarasinghe et al. (2018), we apply our model in such a way to allow for the analysis of two-way feedbacks, rather than focusing on more specific predictor-predictand relationships. We refine a standard VAR model by applying a regularization criterion; the advantages of this approach and the details of its implementation are discussed in section 2c. Furthermore, nearly all previous explorations of Arcticmidlatitude connections using Granger causality and VAR methods have been performed on univariate time series data. Here, instead of representing the midlatitude circulation with univariate climate indices, we analyze the midlatitude circulation in a full spatiotemporal field by creating an individual regression model of 500-hPa geopotential height at each grid point. This twodimensional approach allows us to explicitly account for the spatial heterogeneity of Arctic-midlatitude teleconnections without making any a priori assumptions about key regions. 


\section{Data and methods}

\section{a. Data}

We use NASA's Modern-Era Retrospective Analysis for Research and Applications, version 2 (MERRA-2; Gelaro et al. 2017). We represent the midlatitude circulation with $500 \mathrm{hPa}$ geopotential height at every grid point $\left(Z_{500}\right) ; Z_{500}$ has dimensions of (longitude $\times$ latitude $\times$ time) and is analyzed over the Northern Hemisphere only at $1^{\circ}$ spacing in latitude and $1.25^{\circ}$ spacing in longitude. The Arctic is represented by the $850-\mathrm{hPa}$ temperature from $70^{\circ}$ to $90^{\circ} \mathrm{N}\left(T_{\text {polar }}\right) . T_{\text {polar }}$ is averaged both zonally and meridionally and thus has dimensions of $(1 \times$ time $)$. For both variables, we use the years 1980-2017. We remove the seasonal cycle from the daily data by subtracting the mean and the first four Fourier harmonics. The daily data are then averaged into nonoverlapping 5-day chunks to smooth out higher-frequency variability. For this work, we focus only on boreal winter (December-February).

\section{b. Granger causality}

Throughout this manuscript, we work within the framework of Granger causality (Granger 1969). Granger causality frames causal relationships in terms of added predictability-that is, it assesses whether or not a given variable adds predictive power beyond the predictand's ability to forecast itself [see McGraw and Barnes (2018) for a more thorough discussion of Granger causality]. First developed as a predictive econometric modeling tool, Granger causality has more recently found applications in climate science, including, but not limited to, the influence of sea surface temperature on atmospheric variability (e.g., Mosedale et al. 2006) and hurricane strength (e.g., Elsner 2006, 2007), snow cover's influence on surface temperature (e.g., Kaufmann et al. 2003), the impact of ENSO on the Indian monsoon (e.g., Mokhov et al. 2011), and detection and attribution of global temperature increases (see Attanasio et al. 2013, and references therein). By requiring that the predictor must explain a significant amount of variance beyond that of the predictand, Granger causality thus imposes a more stringent criterion for identifying a causal relationship than a standard lagged linear regression, and is less likely to overreport significant relationships due to its accounting for the effects of autocorrelation. We note that, like any approach, Granger causality analysis has its limitations - in particular, the analysis can be influenced by the presence of a confounding variable. That is, an additional variable not included in the Granger causality model could be influencing the variables that have been included in the model, thus leading to a conclusion that there is a causal relationship between two variables when in fact they are both driven by a third process. Basic Granger causality analysis also typically requires the assumptions of linearity and stationarity, although approaches for nonstationary processes have also been developed (e.g., Kaufmann and Stern 2002; Attanasio et al. 2012, 2013). To evaluate whether or not $T_{\text {polar }}$ Granger causes variability in $Z_{500}$ (and vice versa), we set up a VAR model, similar to Strong et al. (2009), which we then further modify with a regularization scheme.

\section{c. Deriving the LASSO model}

We model the relationship between $Z_{500}$ and $T_{\text {polar }}$ with a $p$ th-order VAR model, which predicts each model variable using lagged values of all the model variables (e.g., Lütkepohl 2007). We further modify the VAR model with a regularization scheme, which reduces a full VAR model to a sparse model that selects only the predictors that have the strongest impact on the predictability of the response (e.g., Hastie et al. 2001). That is, a regularized regression model identifies only the most important predictors, and reduces the likelihood of overfitting the model. Here, we use the least absolute shrinkage and selection operator (LASSO; e.g., Tibshirani 1996; Hastie et al. 2015; Nicholson et al. 2017) approach to identify only the key predictors.

First, we create our full, nonregularized VAR model. Here, as we are interested in the two-way relationships between $Z_{500}$ and $T_{\text {polar }}$, we apply a two-variable $p$ th-order VAR model to the anomalies of $Z_{500}$ and $T_{\text {polar }}$,

$$
\begin{aligned}
Z_{500}(t)= & a_{1} Z_{500}(t-1)+a_{2} Z_{500}(t-2)+\cdots \\
& +a_{p} Z_{500}(t-p)+\cdots \\
b_{1} & T_{\text {polar }}(t-1)+b_{2} T_{\text {polar }}(t-2)+\cdots \\
& +b_{p} T_{\text {polar }}(t-p)+\epsilon_{1, t}, \quad \text { and } \\
T_{\text {polar }}(t)= & c_{1} Z_{500}(t-1)+c_{2} Z_{500}(t-2)+\cdots \\
& +c_{p} Z_{500}(t-p)+\cdots \\
d_{1} & T_{\text {polar }}(t-1)+d_{2} T_{\text {polar }}(t-2)+\cdots \\
& +d_{p} T_{\text {polar }}(t-p)+\epsilon_{2, t},
\end{aligned}
$$

where $\epsilon_{1, t}$ and $\epsilon_{2, t}$ are error terms. We note that we do not allow $Z_{500}$ and $T_{\text {polar }}$ to influence each other simultaneously, which allows us to use the simpler form of VAR seen in Eq. (1). Equation (1a) uses lagged values of $Z_{500}$ and $T_{\text {polar }}$ to predict $Z_{500}$-the $a$ coefficients quantify $Z_{500}$ 's influence on itself, while the $b$ coefficients quantify the influence of $T_{\text {polar }}$ on $Z_{500}$. Similarly, in Eq. (1b), lagged values of $Z_{500}$ and $T_{\text {polar }}$ are used to predict $T_{\text {polar }}$-the $c$ coefficients quantify $Z_{500}$ 's 
influence on $T_{\text {polar }}$, while the $d$ coefficients quantify the influence of $T_{\text {polar }}$ on itself. We then assess Eq. (1) for added predictive power by, for example, comparing predictions of $Z_{500}$ with and without $T_{\text {polar }}$. That is, we compare Eq. (1) to a version of Eq. (1) in which the $b$ coefficients are set to zero. If including information about $T_{\text {polar }}$ significantly improves our ability to predict $Z_{500}$, we can say that $T_{\text {polar }}$ is a Granger cause of $Z_{500}$.

Often, the full, nonregularized VAR model is assessed collectively for Granger causality using a metric such as an $F$ test or a likelihood score to determine added predictive power [see Sims (1980), and discussion in the online supplemental material]. This means that regression coefficients cannot be identified as significant or not significant on an individual basis. For example, in Eq. (1), when we evaluate if $T_{\text {polar }}$ is a Granger cause $Z_{500}$, we ask whether or not variables corresponding to all $b$ coefficients collectively increase our ability to predict $Z_{500}$. Thus, by design, either all $b$ coefficients will be included in the model, or none of them will be. One limitation of such an approach is the fact that many coefficients are close to, but not exactly zero. But as we are not evaluating the significance of the coefficients individually, it is difficult to determine which coefficients are the most important predictors, and which are simply noise. A user-defined threshold on the magnitude of the coefficients could be applied-coefficients above this threshold would be retained, while coefficients smaller than this threshold would be discarded. However, such a user-defined threshold can be highly subjective.

Regularized regression provides a less arbitrary approach for identifying key coefficients from a VAR model. When we modify the VAR model with a LASSO regularization scheme, we can simplify Eq. (1) to a sparse model that contains only the most important predictors. The LASSO approach finds a least squares solution that imposes a bound, $\lambda$, on the sum of the absolute values of the regression coefficients; the sparsity of the model (i.e., the number of coefficients set to zero) is controlled by the value of $\lambda$. Practically speaking, this constraint generates a model that is of the same form as Eq. (1), but with many coefficients equaling exactly zero. This means that coefficients that explain the most variability are nonzero, while all other coefficients are exactly zero. Since this approach retains only the most important regression coefficients, it is more easily interpreted, and improves the model's prediction accuracy compared to an ordinary least squares approach (e.g., Tibshirani 1996). In this work, we use a version of the group LASSO approach (i.e., an approach that is designed for predictors with a natural group structure, such as time series data (e.g., Hastie et al. 2015; Nicholson et al. 2017), which is detailed in the appendix of Samarasinghe et al. (2018).

The LASSO model requires careful selection of the regularization parameter $\lambda$. When $\lambda=0$, the LASSO approach is identical to Eq. (1), and as $\lambda$ approaches $\infty$, the solution becomes very sparse (i.e., nearly all coefficients are zero). $\lambda$ selection is thus critical. Here, we select the $\lambda$ using a $K$-fold cross-validation scheme $(k=10)$; the selected $\lambda$ corresponds to the minimum mean squared error plus one standard deviation (e.g., Hastie et al. 2015; Melkumova and Shatskikh 2017; Samarasinghe et al. 2018). We note that this paper focuses on a discussion of the results of the LASSO model, but results from the VAR model alone [Eq. (1), with $\lambda=0$ ] are presented in the supplemental material.

Selecting the maximum lag, represented by $p$, is also important for any lagged regression model. The optimal value of $p$ represents a trade-off between a model with a value of $p$ that is large enough to account for all physically relevant relationships and a model with a value of $p$ that is small enough to yield a model that is easily interpretable. Here, we use a model order of $p=5$ - that is, 5 chunks of 5-day means, implying lagged time scales of up to 25 days. We estimate our optimum $p$ with the Akaike information criterion (Ivanov and Kilian 2005); after this calculation, we establish a model order of $p=5$ (maximum lag of 5, or 25 days) for all grid points.

\section{Results}

We first analyze the results of the LASSO model applied in two dimensions $-Z_{500}$ at every grid point, and $T_{\text {polar }}$ averaged over the polar cap-in section 3a. This two-dimensional approach allows us to clearly identify both regions that are influenced by the Arctic ( $T_{\text {polar }}$ driving $Z_{500}$ ), and regions that influence the Arctic ( $Z_{500}$ driving $T_{\text {polar }}$ ), as well as the time scales over which these relationships operate. After we characterize the full spatiotemporal Arctic-midlatitude relationships in section 3a, we select key regions for further analysis in section $3 \mathrm{~b}$. We separate these regions into those dominated by $T_{\text {polar }}$ driving $Z_{500}$, and those dominated by $Z_{500}$ driving $T_{\text {polar }}$. We discuss the implications of these results in section 4 .

\section{a. Two-dimensional LASSO model}

We use the LASSO model described in section 2 to explore the relationship between Arctic temperatures $\left(T_{\text {polar }}\right)$ and the midlatitude circulation $\left(Z_{500}\right)$ in the MERRA-2 reanalysis. As discussed in section 2c, in a LASSO model, coefficients are either zero or nonzero; thus, by definition, any coefficient seen in Figs. 1 and 2 is viewed as a Granger cause of $T_{\text {polar }}$ or $Z_{500}$, respectively. 


\section{$T_{\text {polar }}$ driving $Z_{500}$}
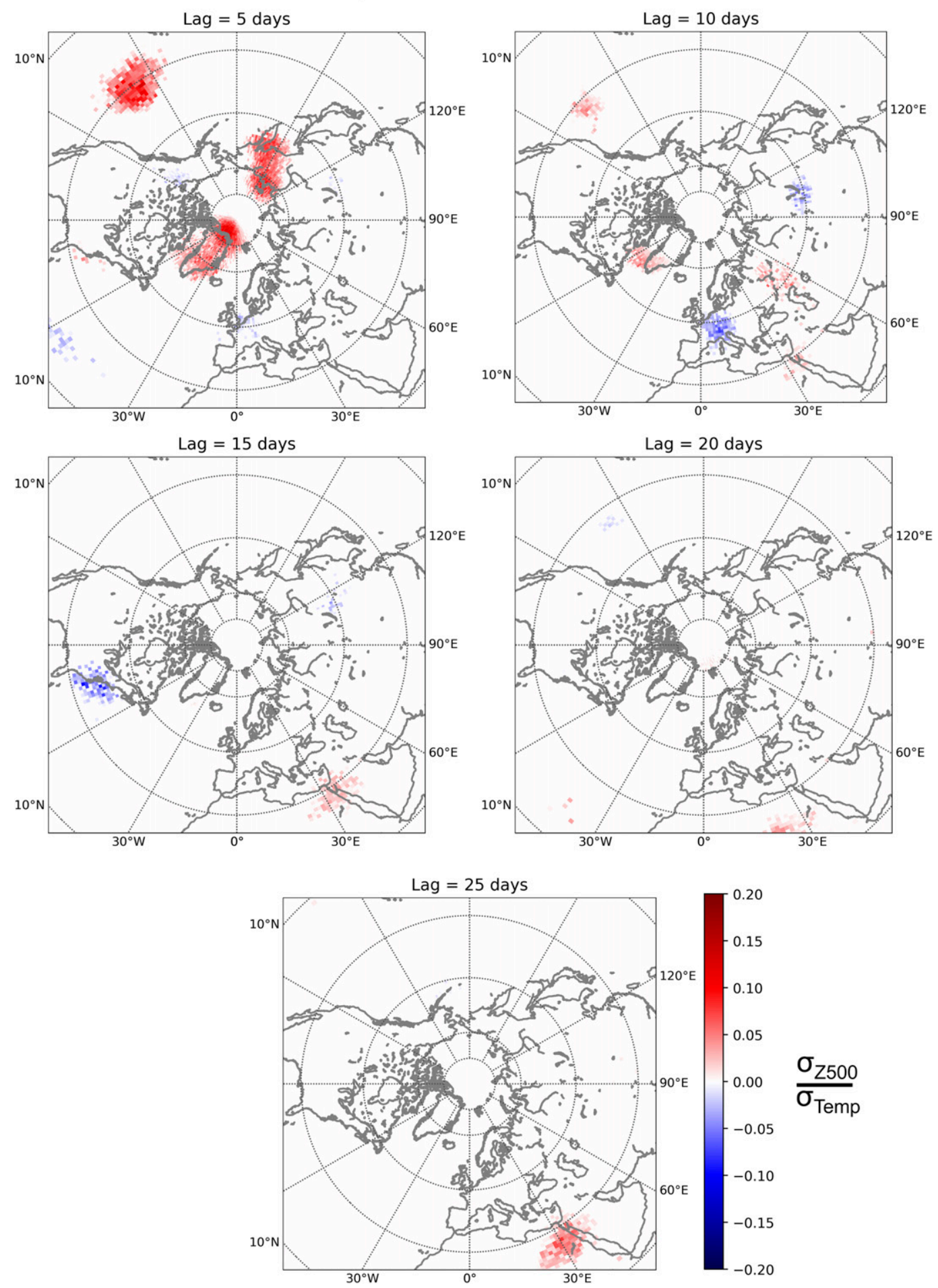

FIG. 1. LASSO model of $T_{\text {polar }}$ driving $Z_{500}$ at each grid point at lags of (a) 5 to (e) 25 days. The shading is in units of standardized LASSO coefficients $\left(\sigma_{Z_{500}} / \sigma_{\text {temp }}\right)$. 


\section{$Z_{500}$ driving $T_{\text {polar }}$}

(a) $\operatorname{Lag}=5$ days

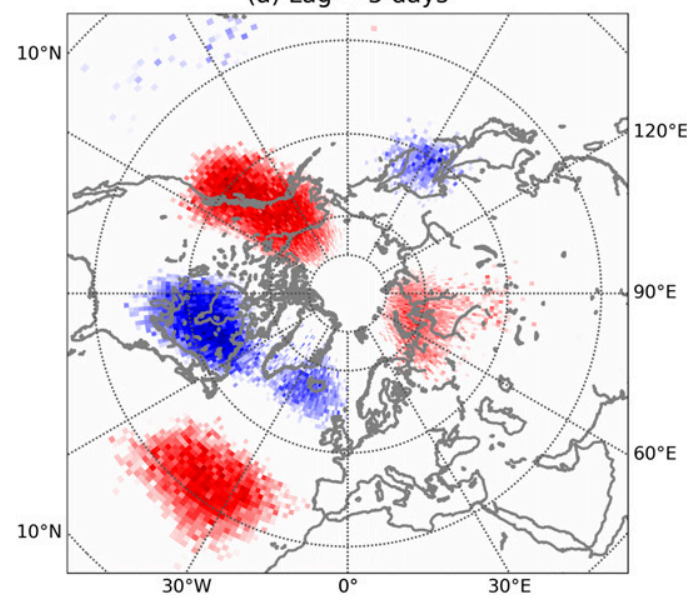

(c) $\mathrm{Lag}=15$ days

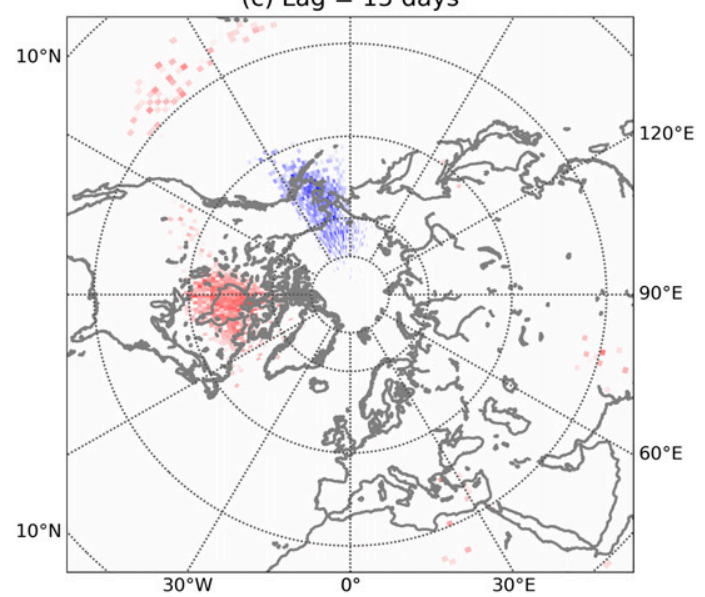

(b) Lag $=10$ days

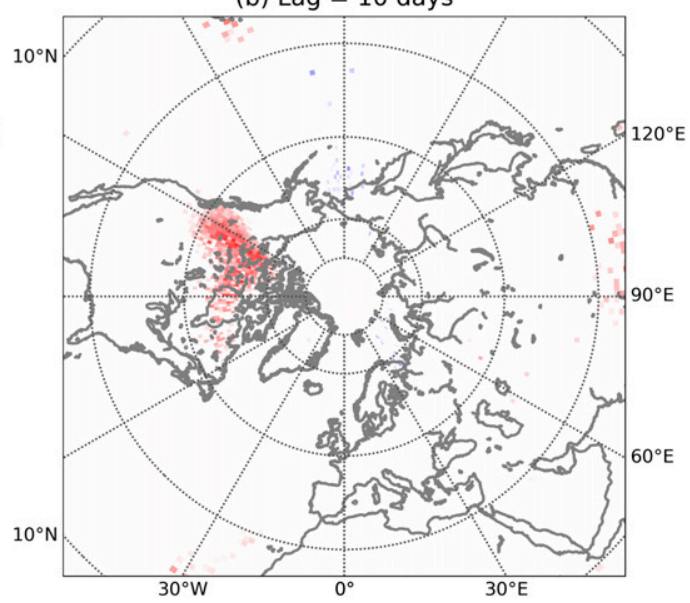

(d) $\operatorname{Lag}=20$ days

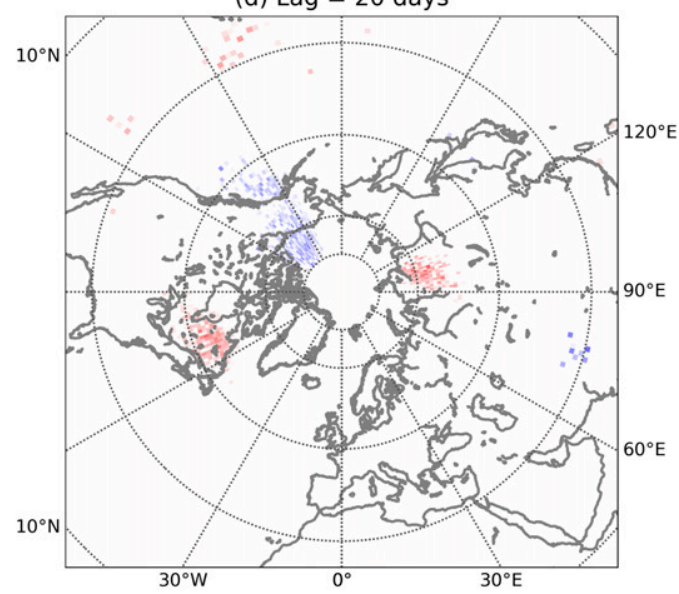

(e) $\operatorname{Lag}=25$ days

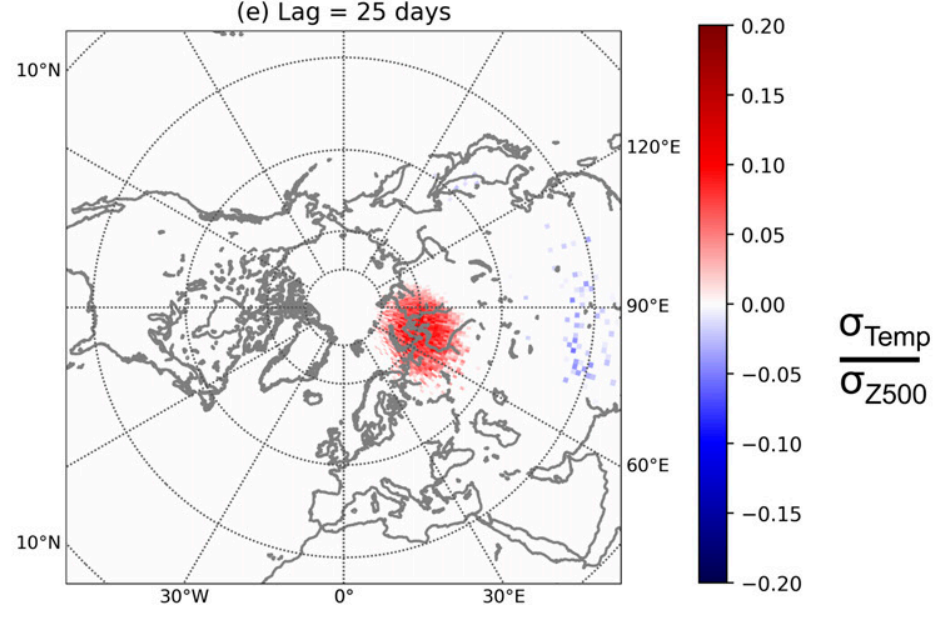

FIG. 2. LASSO model of $Z_{500}$ at each grid point driving $T_{\text {polar }}$ at lags of (a) 5 to (e) 25 days. The shading is in units of standardized LASSO coefficients $\left(\sigma_{\text {temp }} / \sigma_{Z_{500}}\right)$. 
We note that both $Z_{500}$ and $T_{\text {polar }}$ exhibit autocorrelation [ $a$ and $d$ coefficients, respectively, in Eq. (1); not shown]. Like many variables, temperature and geopotential height are typically modeled as "red noise" processes - that is, they have some memory of their past states. As expected, this autocorrelation is strongest at shorter lags and decays at longer lags. The VAR model separates the prediction of, for example, $Z_{500}$ into an autocorrelated component [i.e., $Z_{500}$ predicting $Z_{500}, a$ coefficients in Eq. (1a)] and a cross-correlated component [i.e., $T_{\text {polar }}$ predicting $Z_{500}, b$ coefficients in Eq. (1a)]; thus, the influence of autocorrelation on the cross-correlated components is limited, and our Granger definition of causality (based on additional predictability beyond autocorrelation, as discussed in section $2 \mathrm{~b}$ ) is satisfied.

Figure 1 shows the results of the LASSO model of $T_{\text {polar }}$ driving $Z_{500}$ in units of $\sigma_{Z_{500}} / \sigma_{T_{\text {polar }}}$ [the $b$ terms in Eq. (1a), with $\sigma_{Z_{500}}$ representing the standard deviation in $Z_{500}$, and $\sigma_{T_{\text {polar }}}$ representing the standard deviation in $\left.T_{\text {polar }}\right]$. That is, Fig. 1 indicates the regions in which variability in Arctic temperatures Granger cause variability in the local 500-hPa heights. Red grid points in Fig. 1 indicate a positive lagged relationship, in which warm Arctic temperature anomalies drive high height anomalies at that grid point; blue grid points in Fig. 1 indicate a negative lagged relationship in which warm Arctic temperature anomalies drive low height anomalies at that grid point. At lag day 5 (Fig. 1a), a few regions show a sensitivity to $T_{\text {polar }}$-warm Arctic temperature anomalies drive positive height anomalies over much of Greenland, far eastern Russia and Kamchatka, and the central Pacific. At lag day 10 (Fig. 1b), sparse regions of nonzero relationships between Arctic temperature and $Z_{500}$ remain over the central Pacific and Greenland and also are evident over Europe and the Urals. By lag day 15 and beyond, few regions' circulation anomalies appear to be driven by Arctic temperatures (Fig. 1c). Thus, at 5-25-day time scales, the Arctic temperature driving midlatitude circulation ( $T_{\text {polar }}$ driving $Z_{500}$ ) relationship is primarily important at shorter time scales, with the strength of these relationships maximizing at lag day 5 . A recent review by Cohen et al. (2018) has also highlighted the dominance of shorter time scales in Arctic temperatures driving midlatitude circulation, reinforcing the importance of these relationships at 5-day lags.

We note that we only explore relatively short time scales here, at lags of 25 days or shorter. Many recent studies have focused on a stratospheric pathway of influence from the Arctic to the midlatitudes-broadly speaking, this hypothesis purports that warm temperature anomalies in the Arctic (with a particular emphasis on the Barents-Kara Sea region) drive changes in vertical wave activity, which act to modify and disrupt the stratospheric polar vortex, ultimately affecting the tropospheric circulation (e.g., Peings and Magnusdottir 2014; Sun et al. 2015; Wu and Smith 2016; Screen 2017; Zhang et al. 2018a). Twenty-five days is likely not a sufficient amount of time to capture the impacts of these lower-frequency processes, and thus, our results do not preclude the possibility of Arctic temperatures indirectly influencing the midlatitude circulation indirectly via the stratosphere on longer time scales.

Figure 2 displays the LASSO model of $Z_{500}$ driving $T_{\text {polar }}$ in units of $\sigma_{T_{\text {polar }}} / \sigma_{Z_{500}}$ [the $c$ terms in Eq. (1b)]. Figure 2 highlights the regions in which the circulation at each grid point (represented by $Z_{500}$ ) Granger causes Arctic temperature variability. Again, red grid points indicate a positive lagged relationship (high height anomalies at that grid point driving warm Arctic temperature anomalies), and blue grid points indicate a negative lagged relationship (low height anomalies at that grid point driving warm Arctic temperature anomalies). At lag day 5 (Fig. 2a), many regions show a nonzero relationship between local $Z_{500}$ (i.e., $Z_{500}$ at that grid point) and polar temperatures. Over Alaska, the Beaufort Sea, and the east Pacific, as well as Siberia and the Barents-Kara Seas, high $Z_{500}$ anomalies drive warm Arctic anomalies; over the Sea of Okhotsk and the western Pacific, and eastern Canada, and Greenland and Iceland, low $Z_{500}$ anomalies drive warm Arctic anomalies (Fig. 2a), consistent with the advection of warm, moist, maritime air from the North Atlantic and North Pacific regions into the Arctic. Remotely, at lag day 5, high height anomalies over the Atlantic also drive warm Arctic anomalies (Fig. 2a). The wave-2-like anomalies in Fig. 2a resemble an enhancement of the zonally asymmetric circulation (defined as the time-mean of $Z_{500}$ with the zonal mean removed; seen in Fig. 3a), with the notable exception of over western Europe, where there is no nonzero relationship in the LASSO model. Previous studies (e.g., Baggett et al. 2016; Graversen and Burtu 2016; Messori et al. 2018) have also linked Arctic warming with enhancement of the climatological planetary-scale wave activity and increased warm air advection into the Arctic.

The pattern seen at lag day 5 is not evident at lag day 10 (Fig. 2b). At lag days 10-20 (Figs. 2b-d), there are some regions that exhibit significant responses in the LASSO model, albeit at smaller spatial scales and magnitudes than seen in Fig. 2a. At lag day 15, for example, a region of anomalously high $Z_{500}$ over eastern Canada and Hudson Bay and a region of anomalously low $Z_{500}$ over Alaska drive warm Arctic temperature anomalies 15 days later (Fig. 2c). These anomalies may be precursors to the pattern seen in Fig. 2a at lag day 5 . 
(a) Zonal Anomalies of $Z_{500}$ (DJF)

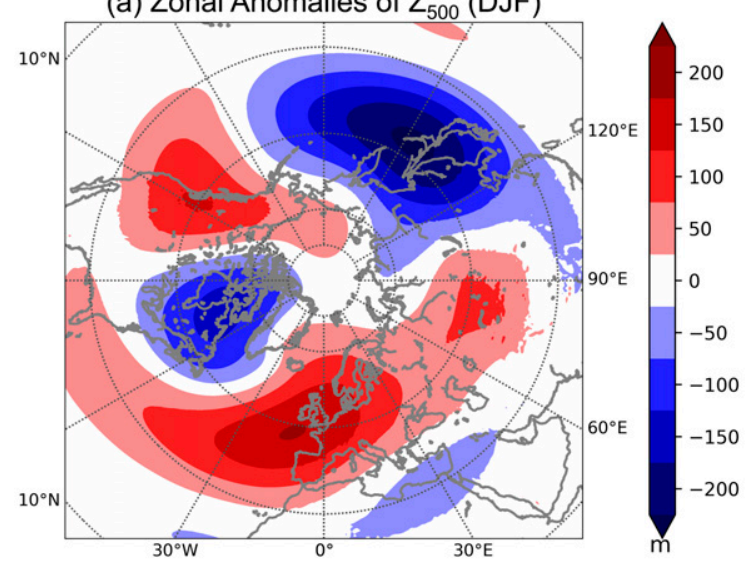

(b) Lag $=5$ days, $Z_{500}$ driving $T_{\text {polar }}$

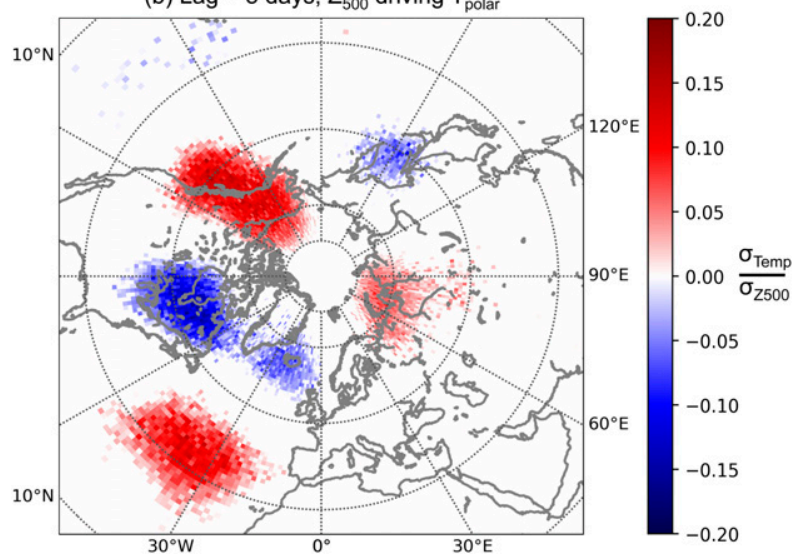

FIG. 3. (a) Zonal anomalies of the time-mean 500-hPa geopotential heights in DJF. (b) Fig. 2a (LASSO model of $Z_{500}$ at each grid point driving $T_{\text {polar }}$ at lag day 5), reprinted for comparison.

Around lag day 20, a signal begins to reemerge over Siberia, with high $Z_{500}$ anomalies driving warm Arctic temperatures (Fig. 2d). While this region of positive LASSO coefficients is small at lag day 20 , by lag day 25 , the region of positive LASSO coefficients is much larger and stronger, linking high height anomalies over Siberia and the Barents-Kara Seas to warm Arctic temperatures 25 days later (Fig. 2e).

Figures 1 and 2 display the results of the LASSO models for $T_{\text {polar }}$ driving $Z_{500}$, and $Z_{500}$ driving $T_{\text {polar }}$, respectively. In the case of both models, 37 years of MERRA-2 reanalysis shows nonzero results for 5-25day time scales in many regions. Additionally, the regions in which Arctic temperatures drive variability in the midlatitude circulation are not the same regions as those where the midlatitude circulation drives Arctic temperature variability. More specifically, Arctic temperatures Granger cause circulation responses over eastern Russia, the central Pacific, and Greenland at lags of up to 10 days (Figs. 1a,b), and have little influence over the midlatitude circulation at greater lags (Figs. 1c-e). The midlatitude circulation, however, Granger causes a nonzero Arctic temperature response via enhancement of the existing stationary wave pattern at lag day 5 (Fig. 2a), and $Z_{500}$ anomalies over Alaska, the Beaufort Sea, and Hudson Bay at lags of up to 20 days (Figs. 2b-d). Beginning at lag day 20 , the signal over Siberia begins to reemerge, with positive height anomalies over Siberia and the Barents-Kara Seas driving warm Arctic anomalies at lag days 20-25 (Figs. 2d,e).

\section{b. Regional analysis}

The results of Figs. 1 and 2 emphasize the regional variability of Arctic-midlatitude teleconnections. For example, sea ice loss in specific regions has been linked to large-scale midlatitude circulation anomalies. Atlantic and Pacific ice loss produce not only different but opposing responses in the North Atlantic Oscillation (e.g., Sun et al. 2015; Pedersen et al. 2016); Koenigk et al. (2016) and Screen (2017) provide more extensive regional analyses of the impact of Arctic sea ice loss on the midlatitude circulation, using correlation analysis on ERA-Interim reanalysis (Koenigk et al. 2016) and a suite of AGCM experiments forced by sea ice loss (Screen 2017). We note that these studies focus almost exclusively on the variability of the atmospheric response to sea ice loss in different regions rather than two-way responses, and that they are primarily concerned with this response on longer time scales than we consider here.

In contrast to previous studies (e.g., Sun et al. 2015; Pedersen et al. 2016; Koenigk et al. 2016; Screen 2017), we additionally focus on how different regions' circulation patterns (as represented by $Z_{500}$ ) impact pan-Arctic climate on submonthly time scales. In this way, we can more closely examine Arctic-midlatitude relationships in terms of two-way feedbacks, and how the midlatitude circulation and the Arctic simultaneously impact each other. To do this, we identify key regions based on the results of Figs. 1 and 2 for regional analysis. The regions of interest are listed in Table 1 , and they can be geographically identified in Fig. 6d. $Z_{500}$ is averaged over the area of each region in Table 1, giving it the dimensions of $(1 \times$ time $)$. As in the previous section, $T_{\text {polar }}$ is averaged over all longitudes from $70^{\circ}$ to $90^{\circ} \mathrm{N}$, with dimensions of $(1 \times$ time $)$. Thus, instead of applying the LASSO model to each grid point separately, we simply have one LASSO model for each region. By simplifying our variables to two time series, we are able to represent our results in graphical form [see Ebert-Uphoff and Deng (2012) for a thorough discussion of the application of graphical methods to climate science]. That is, our variables $Z_{500}$ and $T_{\text {polar }}$ are represented as nodes on a 
TABLE 1. Region definitions.

\begin{tabular}{lcc}
\hline \multicolumn{1}{c}{ Region } & Latitude & Longitude \\
\hline 1. Atlantic & $25^{\circ}-40^{\circ} \mathrm{N}$ & $15^{\circ}-55^{\circ} \mathrm{W}$ \\
2. Greenland & $55^{\circ}-75^{\circ} \mathrm{N}$ & $0^{\circ}-60^{\circ} \mathrm{W}$ \\
3. Siberia & $50^{\circ}-75^{\circ} \mathrm{N}$ & $50^{\circ}-100^{\circ} \mathrm{E}$ \\
4. West Pacific & $45^{\circ}-70^{\circ} \mathrm{N}$ & $120^{\circ} \mathrm{E}-180^{\circ}$ \\
5. East Pacific & $45^{\circ}-75^{\circ} \mathrm{N}$ & $110^{\circ} \mathrm{W}-180^{\circ}$ \\
6. Central Pacific & $20^{\circ}-50^{\circ} \mathrm{N}$ & $120^{\circ}-160^{\circ} \mathrm{W}$ \\
7. North America & $40^{\circ}-65^{\circ} \mathrm{N}$ & $60^{\circ}-100^{\circ} \mathrm{W}$ \\
\hline
\end{tabular}

graph, while the edges delineate the connections between the nodes. Our regions are defined based on the results of Figs. 1 and 2; nevertheless, they are not overly sensitive to the exact location of the regional boundaries, even when the latitudinal extent is reduced by as much as $20 \%$. As in Figs. 1 and 2, the results are presented as standardized LASSO coefficients $(\sigma / \sigma)$.

Figures 4 and 5 show the results of the one-dimensional LASSO model applied to each region in Table 1. Figure 4 contains the regions in which $Z_{500}$ drives $T_{\text {polar }}$, while Fig. 5 contains the regions in which $T_{\text {polar }}$ drives $Z_{500}$; these relationships will be discussed shortly.

As expected, both $Z_{500}$ and $T_{\text {polar }}$ exhibit autocorrelation in all regions (curved arrows in Figs. 4 and 5), with the largest autocorrelation occurring at lag day 5 , and decreasing at longer lags. For $Z_{500}$, at lag day 5 , the LASSO coefficients range from 0.26 to 0.45 . In some regions (specifically, the east Pacific), substantial autocorrelation in $Z_{500}$ persists at lags up to 20 days. For $T_{\text {polar }}$, this memory only exists up to 5 days, with a LASSO coefficient around 0.4 in all regions.

An examination of the $Z_{500}$ driving $T_{\text {polar }}$ (Fig. 4) and $T_{\text {polar }}$ driving $Z_{500}$ (Fig. 5) coefficients $[c$ and $b$ coefficients in Eq. (1)] reveals that in all regions, there is one dominant relationship - that is, either Arctic temperatures Granger cause variability in the midlatitude circulation (Fig. 5), or the midlatitude circulation Granger causes Arctic temperature variability (Fig. 4). In the Atlantic, Siberia, the east Pacific, Greenland, and North America, the midlatitude circulation drives anomalies in Arctic temperature, but Arctic temperature does not drive any nonzero anomalies in the local circulation in these regions (Figs. 4a-d; regions 1, 2, 3, 5, and 7 in Table 1). Over the Atlantic, Siberia, and the east Pacific, at lag day 5, high local height anomalies drive warm anomalies in Arctic temperature (Figs. 4a-c; regions 1, 3 , and 5 in Table 1). Over Greenland and North America, at lag day 5, the relationship is opposite-low height anomalies over North America and Greenland drive warm anomalies in Arctic temperature (Fig. 4d; regions 2 and 7 in Table 1). At lag days 15 and 20, however, high height anomalies over North America drive warm Arctic temperature anomalies; a negative relationship between $Z_{500}$ over the east Pacific and Arctic temperature also reappears at lag day 20. As seen in Fig. 2e, there is a reemergence of a signal over Siberia at the longest lags - at lag day 25, high height anomalies over Siberia are also drivers of warm Arctic temperature anomalies (Fig. 4b; region 3 in Table 1).

By contrast, over the west and central Pacific, Arctic temperature predominantly drives a response in $Z_{500}$ (Fig. 5). Warm Arctic temperature anomalies drive positive $Z_{500}$ anomalies at lag day 5 for both regions (Fig. 5a; regions 4 and 6 in Table 1). In Fig. 1a, Greenland (represented in both Figs. 4e; region 2 in Table 1) shows hints of a two-way feedback relationship-in Fig. 1a, at lag day 5, warm Arctic temperature anomalies drive high $Z_{500}$ anomalies over Greenland, which drive cold Arctic temperature anomalies in 5 days time. However, when we average $Z_{500}$ over the region in Table 1, this relationship is not nonzero according to the LASSO model. We note that we did perform sensitivity tests with regard to the areal extent of the averaging region; in Greenland, the $T_{\text {polar }}$ driving the $Z_{500}$ relationship was sometimes nonzero in these regions. However, in these cases, the strength of the LASSO coefficient (in units of $\sigma / \sigma$ ) for $Z_{500}$ driving $T_{\text {polar }}$ is more than double that of $T_{\text {polar }}$ driving $Z_{500}$, suggesting that this two-way feedback is not of equal strength and that the $Z_{500}$ driving $T_{\text {polar }}$ relationship is dominant.

Figure 6 summarizes the results of Figs. 4 and 5 in the form of maps. All regions show at least one causal relationship at lag day 5 (Fig. 6a), while the connections are much more limited at longer lags. There are causal connections not only between the Arctic and the continental midlatitude regions, but also the Arctic and the subtropical ocean basins. Over the time scales explored in this study (5-25 days), Arctic temperatures do not impact variability in $Z_{500}$ beyond lag day 5 (Fig. $6 \mathrm{~b}$ ) beyond the autocorrelation of $Z_{500}$, while the circulation in some regions impacts Arctic variability up to lag day 25 (Fig. 6e).

\section{Discussion}

The results of the LASSO model applied to $T_{\text {polar }}$ and $Z_{500}$ emphasize several points. First, we note that the regions in which Arctic temperature is a Granger cause of variability in $Z_{500}$ are different from the regions in which $Z_{500}$ Granger causes variability in Arctic temperature. In fact, the LASSO model suggests that on submonthly time scales, many midlatitude regions influence Arctic temperatures rather than are influenced by them. Targeted modeling studies that primarily explore the atmospheric response to Arctic warming or sea 
a) Atlantic

Lag

$a_{i}$
0.39

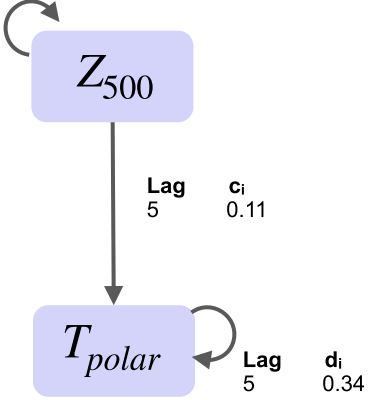

25-40N, 15-55W

c) East Pacific

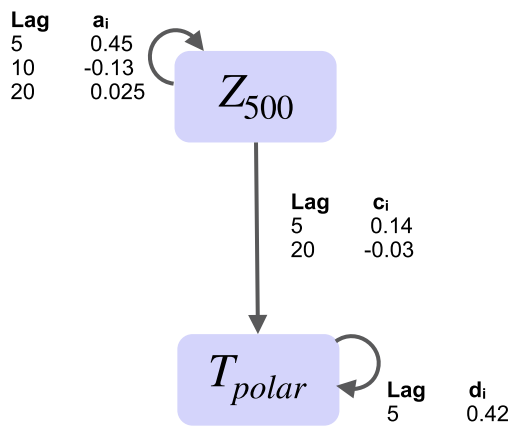

$45-75 \mathrm{~N}, 110-180 \mathrm{~W}$ b) Siberia

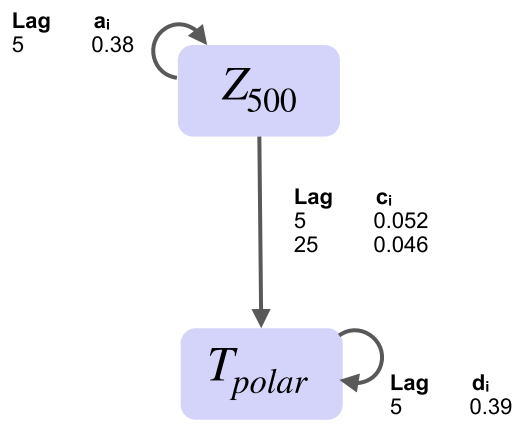

50-75N, 50-100E

d) North America

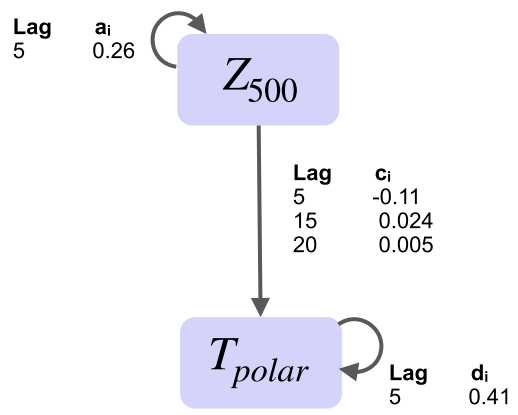

$40-65 N, 60-100 \mathrm{~W}$

\section{e) Greenland}

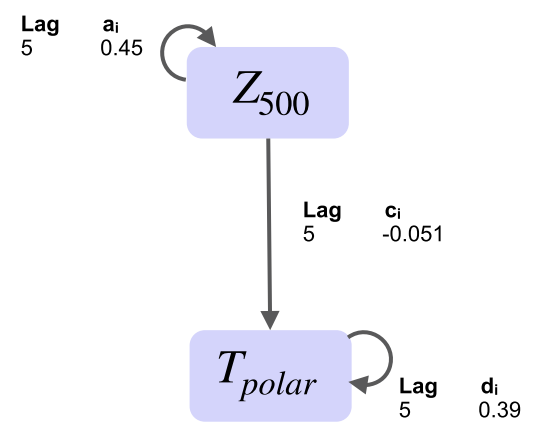

55-75N, 0-60W

FIG. 4. Graphical representation of Arctic-midlatitude causal connections for regions in which $Z_{500}$ drives $T_{\text {polar }}$. Region boundaries are given in Table 1. Curved arrows represent autocorrelation, while straight arrows represent the cross-correlation terms.

ice loss have many advantages, chief among them being that they encourage the thorough testing of physical hypotheses. However, both directions of influence must be considered in order to comprehensively understand the full implications of Arctic-midlatitude teleconnections, thus emphasizing the utility of approaches like the LASSO model outlined here. Here, we briefly note that we also performed the analysis in section $3 \mathrm{~b}$ using a standard lagged linear regression approach. Broadly speaking, a standard lagged linear regression model yields a higher number of significant lagged relationships between $Z_{500}$ and $T_{\text {polar }}$ than a LASSO model. In some regions, such 


\section{a) West Pacific}

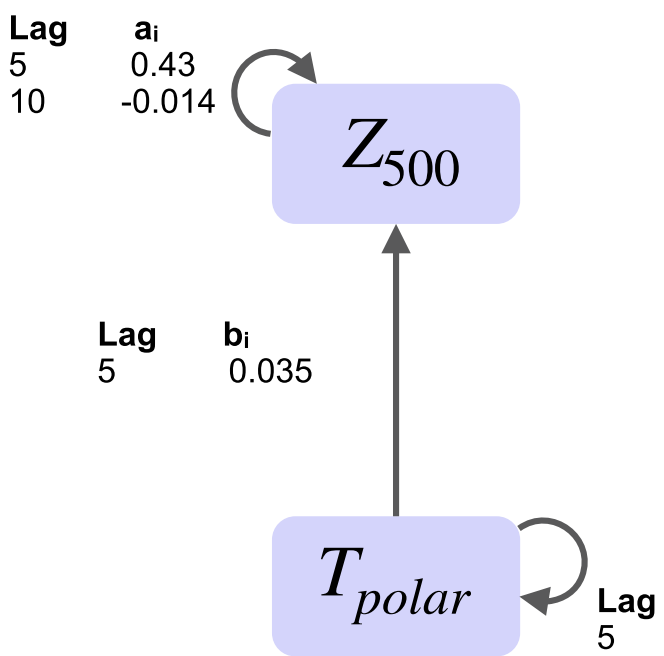

$\mathbf{d}_{\mathrm{i}}$

\section{5-70N, 120-180E}

\section{b) Central Pacific}

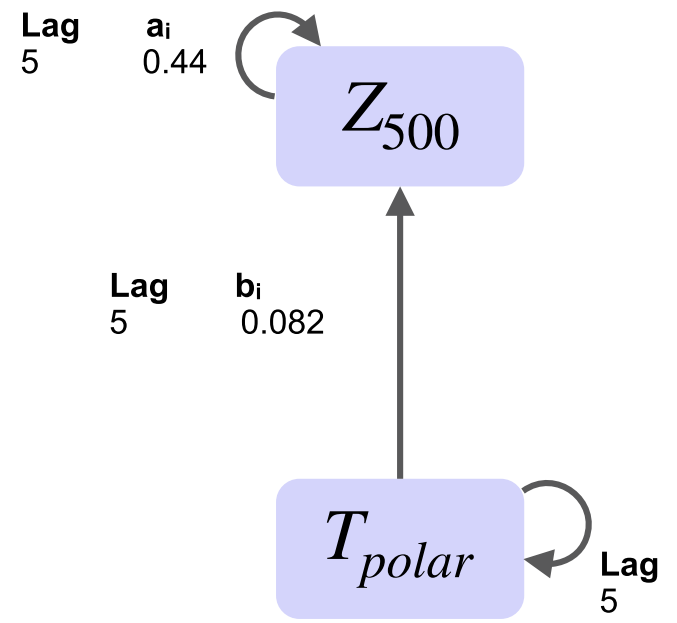

$\mathbf{d}_{\mathrm{i}}$

\section{0-40N, 120-160W}

FIG. 5. Graphical representation of Arctic-midlatitude causal connections for regions in which $T_{\text {polar }}$ drives $Z_{500}$. Region boundaries are given in Table 1. Curved arrows represent autocorrelation, while straight arrows represent the cross-correlation terms.

as the east and west Pacific, the standard lagged linear regression approach and the LASSO model produce largely similar results. In other regions, the standard lagged linear regression model yields some differences compared to the LASSO model-for example, in
Siberia, the standard lagged regression model indicates that the $T_{\text {polar }}$ driving $Z_{500}$ relationship is significant at most or all lags, while the LASSO model does not. These discrepancies suggest that accounting for autocorrelation can yield substantially different results when compared to a model that does not directly account for autocorrelation.

As an example, in recent years, reanalyses have shown a marked cooling and high pressure anomaly over Siberia (e.g., Ogawa et al. 2018). The role of Arctic amplification and sea ice loss in driving this particular feature has been a topic of some scientific interest, with several studies suggesting that anomalously warm Arctic temperatures and/or anomalously low sea ice concentrations (particularly in the Barents-Kara Sea region) could be responsible for driving these cold temperature and high pressure anomalies over Siberia on interannual time scales (e.g., Honda et al. 2009; Inoue et al. 2012; Tang et al. 2013; Mori et al. 2014; Kug et al. 2015; Overland et al. 2015; Luo et al. 2016). These studies primarily apply composite analysis (Inoue et al. 2012; Overland et al. 2015; Luo et al. 2016) or regression or correlation-based models (Honda et al. 2009; Tang et al. 2013; Kug et al. 2015; Overland et al. 2015; Luo et al. 2016) to reanalysis output. While these approaches can show covariability, their capability in determining the direction of the relationship is limited-that is, they can show that warm Arctic temperatures or low sea ice are correlated with cold temperatures or high pressures over Siberia, but they struggle to establish which process drives which in the presence of autocorrelation.

It is in such situations that an approach based on Granger causality, such as the LASSO model utilized in this study, may provide a more robust assessment of causality. The existence of a Granger-causal relationship is established based on the predictor's ability to explain additional variance beyond the autocorrelation of the predictand, imposing a more stringent criterion for establishing a significant relationship (e.g., Runge et al. 2014; McGraw and Barnes 2018). Indeed, our results provide evidence that rather than warm Arctic temperature anomalies driving a strengthening of the Siberian high, it is in fact the other way around-a stronger Siberian high drives a warm temperature anomaly in the Arctic on submonthly time scales. Several recent studies using large ensembles of climate model simulations (e.g., McCusker et al. 2016; Sun et al. 2016; Ogawa et al. 2018) have also suggested that Arctic warming and sea ice loss do not drive significant continental cooling or high pressure responses over Eurasiarather, the observed cooling is simply a manifestation of internal variability. Current studies of sea ice reductions (e.g., Luo et al. 2017, Kelleher and Screen 2018) and 
(a) day 5

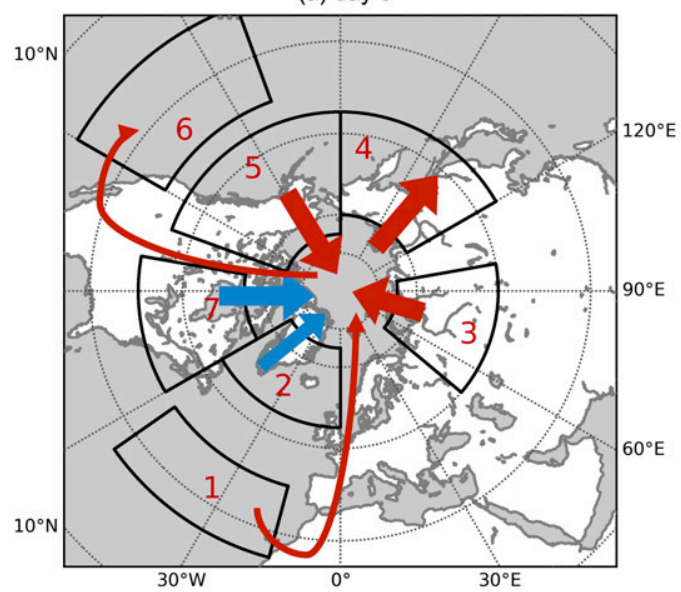

(c) day 15

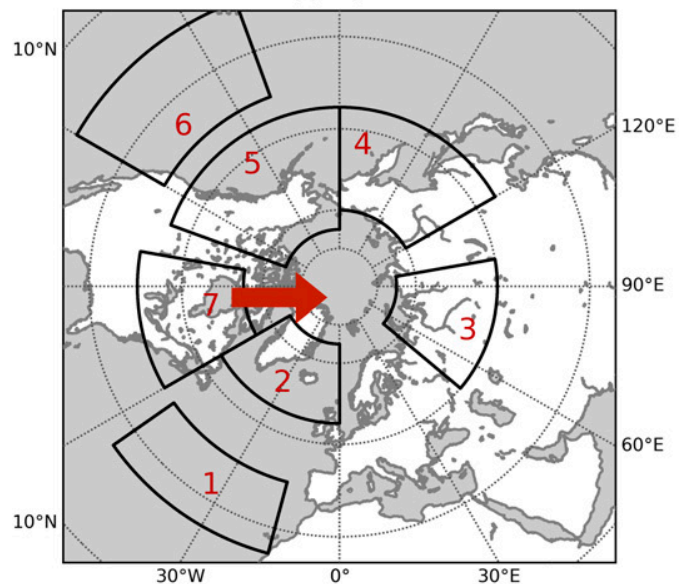

(b) day 10

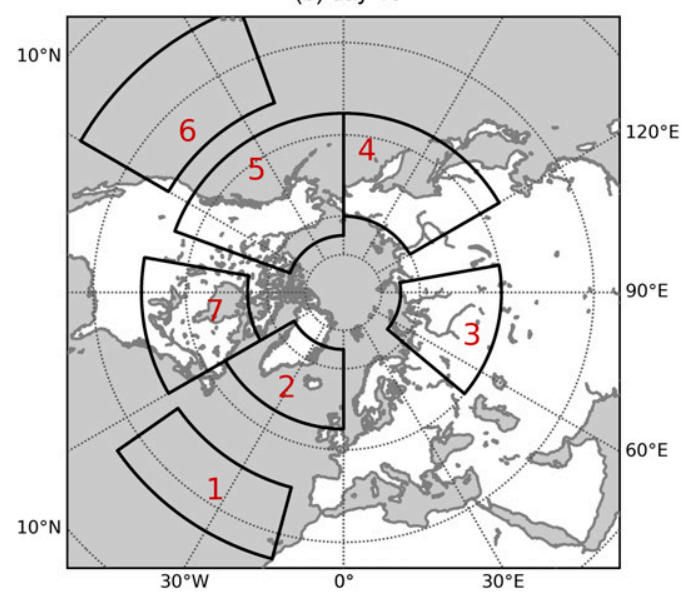

(d) day 20

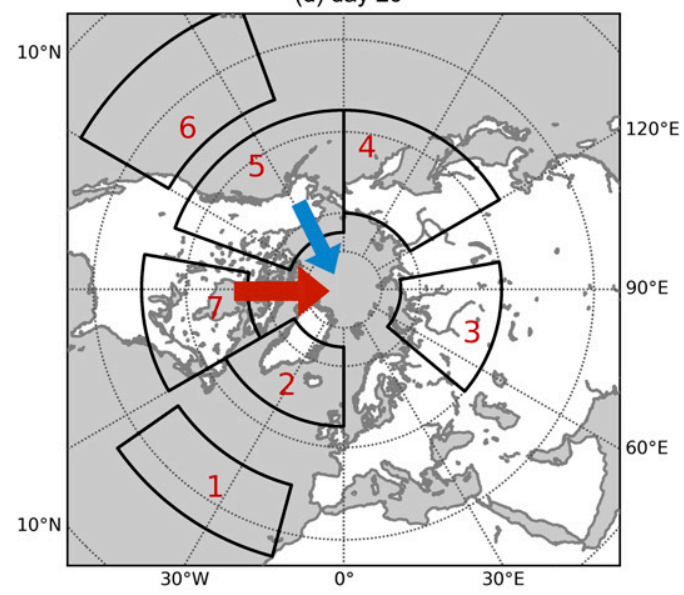

(e) day 25

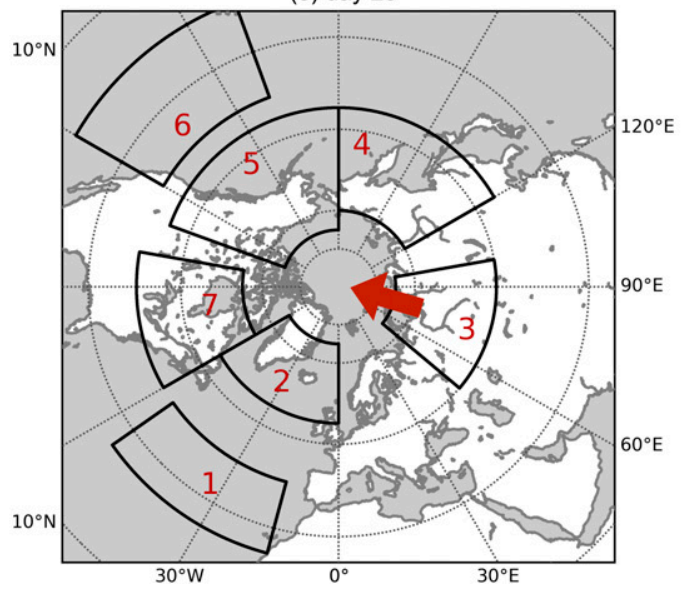

FIG. 6. Simplified schematic of LASSO model results for Arctic-midlatitude causal connections at lags of (a) 5 to (e) 25 days. Arrows pointing into the Arctic indicate regions in which the local circulation $\left(Z_{500}\right)$ is a Granger cause of Arctic temperatures; arrows pointing out of the Arctic indicate regions in which Arctic temperature is a Granger cause of the local circulation $\left(Z_{500}\right)$. Colors indicate the sign of the relationship-red arrows indicate a positive LASSO coefficient (warm Arctic temperature anomalies drive high geopotential height anomalies, and high height anomalies drive warm Arctic temperature anomalies), while blue arrows indicate a negative LASSO coefficient (warm Arctic temperature anomalies drive low geopotential height anomalies, and low height anomalies drive warm Arctic temperature anomalies). 
extreme Arctic temperature events (e.g., Messori et al. 2018) in reanalysis have also hypothesized that high pressure over Eurasia drives a large response in the Arctic on daily to monthly time scales.

The LASSO model results presented here have several novel advantages. This approach can be applied to both climate model output and reanalysis, allowing for a more straightforward comparison between the two. Since the LASSO model is based on a Granger causality approach, it is able to make a stronger statement about causal relationships between Arctic temperatures and the midlatitude circulation than a standard lagged linear regression approach. Specifically, the Granger causality approach also identifies the processes by which the midlatitude atmosphere feeds back upon and modifies the Arctic climate-a pathway that is not fully represented in many targeted modeling studies, as they force Arctic temperatures or sea ice to a certain state. Furthermore, the LASSO model as formulated here inherently takes the regional variability of the circulation into account (Figs. 1 and 2), without having to run large numbers of model simulations. We note that in this study, we focus on the regional variability of the circulation; however, there is also regional variability in Arctic temperatures and sea ice extent (e.g., Sun et al. 2015; Screen 2017), and the modeling approach in this work could also be used to explore the role of regional variability in Arctic temperature on the circulation response.

While there are many advantages to the Granger causality approach employed in this study, we note several important caveats. First, this study is focused entirely on time scales of 25 days or fewer-we do not make any claims regarding interannual or decadal variability, or how these relationships might change in the face of climate change, although we note that we do subtract the first four Fourier harmonics in order to remove the seasonal cycle, which eliminates some interannual variability in the $T_{\text {polar }}$ and $Z_{500}$ variables themselves. Our emphasis on submonthly time scale variability also means that we do not explore the hypothesis that Arctic warming indirectly affects the tropospheric circulation by disturbing the stratospheric polar vortex (e.g., Sun et al. 2015; Wu and Smith 2016; Zhang et al. 2018b,a). We note that while we limit our analysis in this work to lags of 5-25 days, the link between $Z_{500}$ driving $T_{\text {polar }}$ at a lag of 25 days in the Siberia region (Figs. 2e and $4 \mathrm{~b}$ ) could be related to the results of many studies that have linked changes in Barents-Kara Sea ice cover and snow cover over Siberia (e.g., Sun et al. 2015; Wu and Smith 2016; Zhang et al. 2018a,b; Cohen et al. 2014) to changes in the midlatitude circulation via stratosphere-troposphere coupling, which often take multiple weeks to emerge. Second, we note that the LASSO coefficients in Figs. 1, 2, 4, and 5 are small. Some of this is likely due to the nature of the LASSO regression, which acts to reduce the values of the regression coefficients overall (e.g., Hastie et al. 2015); the VAR results, without the LASSO regularization criteria applied, do exhibit somewhat larger values for regression coefficients (see supplemental material). However, the overall low values of regression coefficients are consistent with the results of Barnes and Simpson (2017), who found that Arctic temperatures explained only $1 \%-3 \%$ of additional variance in the midlatitude jet streams on subseasonal time scales-that is, compared to internal variability, the strength of these Arctic-midlatitude teleconnections is not especially large. Finally, we note that the Granger causality analysis used in this work does not permit instantaneous connections, although such connections can be permitted in different formulations of the model (e.g., Strong et al. 2009).

\section{Conclusions}

We have applied a regularized regression model formulated on Granger causality, and its emphasis on added predictive power, to MERRA-2 reanalysis to study submonthly relationships between Arctic temperatures and the midlatitude circulation. The regularized regression model shows evidence of both Arctic temperatures driving midlatitude circulation responses, and midlatitude circulation driving Arctic temperature responses, but rarely in the same location. Arctic temperatures primarily drive circulation responses over the Pacific and Greenland at lags of 10 days or shorter; we do not see evidence of Arctic temperatures driving nonzero responses over North America or most of Eurasia on submonthly time scales. When we focus on specific regions, we find that the circulation in most regions is either driven by Arctic temperatures (the west Pacific, the central Pacific), or is a driver of Arctic temperatures (the subtropical Atlantic, Siberia, the east Pacific, North America, Greenland). In particular, our results over Siberia support the hypothesis that recent observed Eurasian cooling and high pressure anomalies are not driven by warm Arctic anomalies, but rather they are drivers of warm Arctic temperature anomalies. We emphasize that the midlatitude circulation drives substantial variability in Arctic temperatures as well and must be considered when fully evaluating Arcticmidlatitude dynamics.

Acknowledgments. The authors thank Savini Samarasinghe and Imme Ebert-Uphoff for their essential assistance in developing and implementing the VAR and 
LASSO models used in this paper, and for their always helpful discussions of and improvements to our causal discovery methods. Randal Barnes aided us in the implementation of the VAR model. Thanks also to Jingyuan $\mathrm{Li}$, our three reviewers, and the editor for suggestions and feedback regarding this manuscript. The MERRA-2 data used in this study have been provided by the Global Modeling and Assimilation Office (GMAO) at NASA Goddard Space Flight Center. MCM and EAB are supported by the National Science Foundation under Grants AGS-1545675 and AGS-1749261.

\section{REFERENCES}

Attanasio, A., A. Pasini, and U. Triacca, 2012: A contribution of attribution of recent global warming by out-of-sample Granger causality analysis. Atmos. Sci. Lett., 13, 67-72, https://doi.org/ 10.1002/asl.365.

,-- , and,- 2013 : Granger causality analyses for climatic attribution. Atmos. Climate Sci., 3, 515-522, https://doi.org/ 10.4236/acs.2013.34054.

Ayarzagüena, B., and J. Screen, 2016: Future Arctic sea ice loss reduces severity of cold air outbreaks in midlatitudes. Geophys. Res. Lett., 43, 2801-2809, https://doi.org/10.1002/ 2016GL068092.

Baggett, C., and S. Lee, 2017: An identification of the mechanisms that lead to Arctic warming during planetary-scale and synoptic-scale wave life cycles. J. Atmos. Sci., 74, 1859-1877, https://doi.org/10.1175/JAS-D-16-0156.1.

,-- , and S. Feldstein, 2016: An investigation of the presence of atmospheric rivers over the North Pacific during planetaryscale wave life cycles and their role in Arctic warming. J. Atmos. Sci., 73, 4329-4347, https://doi.org/10.1175/JAS-D16-0033.1.

Barnes, E. A., and I. R. Simpson, 2017: Seasonal sensitivity of the Northern Hemisphere jet streams to Arctic temperatures on subseasonal time scales. J. Climate, 30, $10117-10137$, https:// doi.org/10.1175/JCLI-D-17-0299.1.

Blackport, R., and P. Kushner, 2016: The transient and equilibrium climate response to rapid summertime sea ice loss in CCSM4. J. Climate, 29, 401-417, https://doi.org/10.1175/JCLI-D15-0284.1.

- , and -2017 : Isolating the atmospheric circulation response to Arctic sea ice loss in the coupled climate system. J. Climate, 30, 2163-2185, https://doi.org/10.1175/JCLI-D16-0257.1.

Burt, M. A., D. A. Randall, and M. D. Branson, 2016: Dark warming. J. Climate, 29, 705-719, https://doi.org/10.1175/ JCLI-D-15-0147.1.

Butler, A. H., D. W. Thompson, and R. Heikes, 2010: The steadystate atmospheric circulation response to climate change-like thermal forcings in a simple general circulation model. J. Climate, 23, 3474-3496, https://doi.org/10.1175/2010JCLI3228.1.

Cohen, J., J. Furtado, J. Jones, M. Barlow, D. Whittleston, and D. Entekhabi, 2014: Linking Siberian snow cover to precursors of stratospheric variability. J. Climate, 27, 5422-5432, https:// doi.org/10.1175/JCLI-D-13-00779.1.

_, K. Pfeiffer, and J. Francis, 2018: Warm Arctic episodes linked with increased frequency of extreme weather in the United
States. Nat. Commun., 9, 869, https://doi.org/10.1038/ s41467-018-02992-9.

Deser, C., R. A. Tomas, M. Alexander, and D. Lawrence, 2010: The seasonal atmospheric response to projected Arctic sea ice loss in the late twenty-first century. J. Climate, 23, 333-351, https://doi.org/10.1175/2009JCLI3053.1.

Ebert-Uphoff, I., and Y. Deng, 2012: Causal discovery for climate research using graphical models. J. Climate, 25, 5648-5665, https://doi.org/10.1175/JCLI-D-11-00387.1.

Elsner, J. B., 2006: Evidence in support of the climate changeAtlantic hurricane hypothesis. Geophys. Res. Lett., 33, L16705, https://doi.org/10.1029/2006GL026869.

_ 2007: Granger causality and Atlantic hurricanes. Tellus, 59A, 476-485, https://doi.org/10.1111/j.1600-0870.2007.00244.x.

Gelaro, R., and Coauthors, 2017: The Modern-Era Retrospective Analysis for Research and Applications, version 2 (MERRA-2). J. Climate, 30, 5419-5454, https://doi.org/ 10.1175/JCLI-D-16-0758.1.

Granger, C., 1969: Investigating causal relations by econometric models and cross-spectral methods. Econometrica, 37, 424-438, https://doi.org/10.2307/1912791.

Graversen, R. G., and M. Burtu, 2016: Arctic amplification enhanced by latent energy transport of atmospheric planetary waves. Quart. J. Roy. Meteor. Soc., 142, 2046-2054, https:// doi.org/10.1002/qj.2802.

Hastie, T., R. Tibshirani, and J. Friedman, 2001: The Elements of Statistical Learning: Data Mining, Inference, and Prediction. 2nd ed. Springer, 533 pp.

- - — , and M. Wainwright, 2015: Statistical Learning with Sparsity: The Lasso and Generalizations. CRC Press, 367 pp.

Honda, M., J. Inoue, and S. Yamane, 2009: Influence of low Arctic sea-ice minima on anomalously cold Eurasian winters. Geophys. Res. Lett., 36, L08707, https://doi.org/10.1029/ 2008GL037079.

Inoue, J., M. Hori, and K. Takaya, 2012: The role of Barents Sea ice in the wintertime cyclone track and emergence of a warmArctic cold-Siberian anomaly. J. Climate, 25, 2561-2568, https://doi.org/10.1175/JCLI-D-11-00449.1.

Ivanov, V., and L. Kilian, 2005: A practitioner's guide to lag order selection for VAR impulse response analysis. Stud. Nonlinear Dyn. Econom., 9 (1), 1-36, https://doi.org/10.2202/ 1558-3708.1219.

Kaufmann, R. K., and D. I. Stern, 2002: Cointegration analysis of hemispheric temperature relations. J. Geophys. Res., 107, 4012, https://doi.org/10.1029/2000JD000174.

- L. Zhou, R. Myneni, C. Tucker, D. Slayback, N. Shabanov, and J. Pinzon, 2003: The effect of vegetation on surface temperature: A statistical analysis of NDVI and climate data. Geophys. Res. Lett., 30, 2147, https://doi.org/10.1029/ 2003 GL018251.

Kelleher, M., and J. Screen, 2018: Atmospheric precursors of and response to anomalous Arctic sea ice in CMIP5 models. Adv. Atmos. Sci., 35, 27-37, https://doi.org/10.1007/ s00376-017-7039-9.

Koenigk, T., M. Caian, G. Nikulin, and S. Schimanke, 2016: Regional Arctic sea ice variations as a predictor for winter climate conditions. Climate Dyn., 46, 317-337, https://doi.org/ 10.1007/s00382-015-2586-1.

Kretschmer, M., D. Coumou, J. F. Donges, and J. Runge, 2016: Using causal effect networks to analyze different Arctic drivers of midlatitude winter circulation. J. Climate, 29, 40694081, https://doi.org/10.1175/JCLI-D-15-0654.1.

Kug, J.-S., J.-H. Jeong, Y.-S. Jang, B.-M. Kim, C. Folland, S.-K. Min, and S.-W. Son, 2015: Two distinct influences of Arctic 
warming on cold winters of North America and East Asia. Nat. Geosci., 8, 759-762, https://doi.org/10.1038/ngeo2517.

Lee, S., 2014: A theory for polar amplification from a general circulation perspective. Asia-Pac. J. Atmos. Sci., 50, 31-43, https://doi.org/10.1007/s13143-014-0024-7.

Liu, C., and E. A. Barnes, 2015: Extreme moisture transport into the Arctic linked to Rossby wave breaking. J. Geophys. Res., 120, 3774-3788, https://doi.org/10.1002/2014JD022796.

Luo, B., D. Luo, L. Wu, L. Zhong, and I. Simmonds, 2017: Atmospheric circulation patterns which promote winter Arctic sea ice decline. Environ. Res. Lett., 12, 054017, https://doi.org/ 10.1088/1748-9326/aa69d0.

Luo, D., Y. Xiao, Y. Yao, A. Dai, I. Simmonds, and C. Franzke, 2016: Impact of Ural blocking on winter warm Arctic-cold Eurasian anomalies. Part I: Blocking-induced amplification. J. Climate, 29, 3925-3947, https://doi.org/10.1175/JCLI-D-15-0611.1.

Lütkepohl, H., 2007: New Introduction to Multiple Time Series Analysis. Springer, 764 pp.

Matthewman, N. J., and G. Magnusdottir, 2011: Observed interaction between Pacific sea ice and the western Pacific pattern on intraseasonal time scales. J. Climate, 24, 5031-5042, https://doi.org/10.1175/2011JCLI4216.1.

McCusker, K. E., J. Fyfe, and M. Sigmond, 2016: Twenty-five winters of unexpected Eurasian cooling unlikely due to Arctic sea-ice loss. Nat. Geosci., 9, 838-843, https://doi.org/10.1038/ ngeo2820.

-, P. J. Kushner, J. C. Fyfe, M. Sigmond, V. V. Kharin, and C. M. Bitz, 2017: Remarkable separability of circulation response to Arctic sea ice loss and greenhouse gas forcing. Geophys. Res. Lett., 44, 7955-7964, https://doi.org/10.1002/2017GL074327.

McGraw, M. C., and E. A. Barnes, 2018: Memory matters: A case for Granger causality in climate variability studies. J. Climate, 31, 3289-3300, https://doi.org/10.1175/JCLI-D-17-0334.1.

Melkumova, L., and S. Shatskikh, 2017: Comparing ridge and LASSO estimators for data analysis. Procedia Eng., 201, 746-755, https://doi.org/10.1016/j.proeng.2017.09.615.

Messori, G., C. Woods, and R. Caballero, 2018: On the drivers of wintertime temperature extremes in the high Arctic J. Climate, 31, 1597-1618, https://doi.org/10.1175/JCLI-D17-0386.1.

Mokhov, I. I., D. A. Smirnov, P. I. Nakonechny, S. S. Kozlenko, E. P. Seleznev, and J. Kurths, 2011: Alternating mutual influence of El-Niño/Southern Oscillation and Indian monsoon. Geophys. Res. Lett., 38, L00F04, https://doi.org/10.1029/ 2010GL045932.

Mori, M., M. Watanabe, H. Shiogama, J. Inoue, and M. Kimoto, 2014: Robust Arctic sea-ice influence on the frequent Eurasian cold winters in past decades. Nat. Geosci., 7, 869-873, https:// doi.org/10.1038/ngeo2277.

Mortin, J., G. Svensson, R. G. Graversen, M.-L. Kapsch, J. C. Stroeve, and L. N. Boisvert, 2016: Melt onset over Arctic sea ice controlled by atmospheric moisture transport. Geophys. Res. Lett., 43, 6636-6642, https://doi.org/10.1002/ 2016GL069330.

Mosedale, T., D. Stephenson, M. Collins, and T. Mills, 2006: Granger causality of coupled climate processes: Ocean feedback on the North Atlantic Oscillation. J. Climate, 19, 1182-1194, https://doi.org/10.1175/JCLI3653.1.

Newman, M., G. N. Kiladis, K. M. Weickmann, F. M. Ralph, and P. D. Sardeshmukh, 2012: Relative contributions of synoptic and low-frequency eddies to time-mean atmospheric moisture transport, including the role of atmospheric rivers. J. Climate, 25, 7341-7361, https://doi.org/10.1175/JCLI-D-11-00665.1.
Nicholson, W., D. Matteson, and J. Bien, 2017: VARX-L: Structured regularization for large vector autoregressions with exogenous variables. Int. J. Forecasting, 33, 627-651, https:// doi.org/10.1016/j.ijforecast.2017.01.003.

Ogawa, F., and Coauthors, 2018: Evaluating impacts of recent Arctic sea ice loss on the Northern Hemisphere winter climate change. Geophys. Res. Lett., 45, 3255-3263, https://doi.org/ 10.1002/2017GL076502.

Oudar, T., E. Sanchez-Gomez, F. Chauvin, J. Cattiaux, L. Terray, and C. Cassou, 2017: Respective roles of direct GHG radiative forcing and induced Arctic sea ice loss on the Northern Hemisphere atmospheric circulation. Climate Dyn., 49, 3693-3713, https://doi.org/10.1007/s00382-017-3541-0.

Overland, J., J. A. Francis, R. Hall, E. Hanna, S.-J. Kim, and T. Vihma, 2015: The melting Arctic and midlatitude weather patterns: Are they connected? J. Climate, 28, 7917-7932, https://doi.org/10.1175/JCLI-D-14-00822.1.

Park, D.-S. R., S. Lee, and S. B. Feldstein, 2015a: Attribution of the recent winter sea ice decline over the Atlantic sector of the Arctic Ocean. J. Climate, 28, 4027-4033, https://doi.org/ 10.1175/JCLI-D-15-0042.1.

Park, H.-S., S. Lee, S.-W. Son, S. B. Feldstein, and Y. Kosaka, 2015b: The impact of poleward moisture and sensible heat flux on Arctic winter sea ice variability. J. Climate, 28, 5030-5040, https://doi.org/10.1175/JCLI-D-15-0074.1.

Pedersen, R., I. Cvijanovic, P. Langen, and B. Vinther, 2016: The impact of regional Arctic sea ice loss on atmospheric circulation and the NAO. J. Climate, 29, 889-902, https://doi.org/ 10.1175/JCLI-D-15-0315.1.

Peings, Y., and G. Magnusdottir, 2014: Response of the wintertime Northern Hemisphere atmospheric circulation to current and projected Arctic sea ice decline: A numerical study with CAM5. J. Climate, 27, 244-264, https://doi.org/10.1175/JCLID-13-00272.1.

, J. Cattiaux, S. Vavrus, and G. Magnusdottir, 2017: Late twenty-first-century changes in the midlatitude atmospheric circulation in the CESM large ensemble. J. Climate, 30, 5943-5960, https://doi.org/10.1175/JCLI-D-16-0340.1.

Ronalds, B., E. Barnes, and P. Hassanzadeh, 2018: A barotropic mechanism for the response of jet stream variability to Arctic amplification and sea ice loss. J. Climate, 31, 7069-7085, https://doi.org/10.1175/JCLI-D-17-0778.1.

Runge, J., V. Petoukhov, and J. Kurths, 2014: Quantifying the strength and delay of climatic interactions: The ambiguities of cross correlation and a novel measure based on graphical models. J. Climate, 27, 720-739, https://doi.org/10.1175/ JCLI-D-13-00159.1.

, and Coauthors, 2019: Inferring causation from time series in Earth system sciences. Nat. Commun., 10, 2553, https:// doi.org/10.1038/s41467-019-10105-3.

Samarasinghe, S., M. McGraw, E. Barnes, and I. Ebert-Uphoff, 2018: A study of links between the Arctic and the midlatitude jet-stream using Granger and Pearl causality. Environmetrics, 30, e2540, https://doi.org/10.1002/env.2540.

Screen, J. A., 2017: Simulated atmospheric response to regional and pan-Arctic sea ice loss. J. Climate, 30, 3945-3962, https:// doi.org/10.1175/JCLI-D-16-0197.1.

, C. Deser, and L. Sun, 2015: Reduced risk of North American cold extremes due to continued Arctic sea ice loss. Bull. Amer. Meteor. Soc., 96, 1489-1503, https://doi.org/10.1175/BAMS-D14-00185.1.

, and Coauthors, 2018: Consistency and discrepancy in the atmospheric response to Arctic sea-ice loss across climate 
models. Nat. Geosci., 11, 155-163, https://doi.org/10.1038/ s41561-018-0059-y.

Sims, C. A., 1980: Macroeconomics and reality. Econometrica, 48, 1-48, https://doi.org/10.2307/1912017.

Smith, D. M., N. J. Dunstone, A. A. Scaife, E. K. Fiedler, D. Copsey, and S. C. Hardiman, 2017: Atmospheric response to Arctic and Antarctic sea ice: The importance of oceanatmosphere coupling and the background state. J. Climate, $\mathbf{3 0}$, 4547-4565, https://doi.org/10.1175/JCLI-D-16-0564.1.

Strong, C., G. Magnusdottir, and H. Stern, 2009: Observed feedback between winter sea ice and the North Atlantic Oscillation. J. Climate, 22, 6021-6032, https://doi.org/10.1175/ 2009JCLI3100.1.

Sun, L., C. Deser, and R. A. Tomas, 2015: Mechanisms of stratospheric and tropospheric circulation response to projected Arctic sea ice loss. J. Climate, 28, 7824-7845, https://doi.org/ 10.1175/JCLI-D-15-0169.1.

_ J. Perlwitz, and M. Hoerling, 2016: What caused the recent "warm Arctic, cold continents" trend pattern in winter temperatures? Geophys. Res. Lett., 43, 5345-5352, https://doi.org/ 10.1002/2016GL069024.

Tang, Q., X. Zhang, X. Yang, and J. A. Francis, 2013: Cold winter extremes in northern continents linked to Arctic sea ice loss. Environ. Res. Lett., 8, 014036, https://doi.org/10.1088/ 1748-9326/8/1/014036.
Tibshirani, R., 1996: Regression shrinkage and selection via the Lasso. J. Roy. Stat. Soc., 58B, 267-288.

Woods, C., and R. Caballero, 2016: The role of moist intrusions in winter Arctic warming and sea ice decline. J. Climate, 29, 4473-4485, https://doi.org/10.1175/JCLI-D-15-0773.1.

,$- \ldots$, and G. Svensson, 2013: Large-scale circulation associated with moisture intrusions into the Arctic during winter. Geophys. Res. Lett., 40, 4717-4721, https://doi.org/10.1002/ grl.50912.

Wu, Y., and K. Smith, 2016: Response of Northern Hemisphere midlatitude circulation to Arctic amplification in a simple atmospheric general circulation model. J. Climate, 29, 20142058, https://doi.org/10.1175/JCLI-D-15-0602.1.

Zappa, G., F. Pithan, and T. Shepherd, 2018: Multimodel evidence for an atmospheric circulation response to Arctic sea ice loss in the CMIP5 future projections. Geophys. Res. Lett., 45, 1011-1019, https://doi.org/10.1002/2017GL076096.

Zhang, P., Y. Wu, I. Simpson, K. Smith, X. Zhang, B. De, and P. Callaghan, 2018a: A stratospheric pathway linking a colder Siberia to Barents-Kara Sea sea ice loss. Sci. Adv., 4, eaat6025, https://doi.org/10.1126/sciadv.aat6025.

-, , and K. Smith, 2018b: Prolonged effect of the stratospheric pathway in linking Barents-Kara Sea sea ice variability to the midlatitude circulation in a simplified model. Climate Dyn., 50, 527-539, https://doi.org/10.1007/s00382-017-3624-y. 